\title{
A encruzilhada da judicialização da saúde no Brasil sob a perspectiva do Direito Comparado
}

\author{
Comparative law and the crossroads of the judicialization of health in Brazil \\ El derecho comparado y la encrucijada de la judicialización de la salud en Brasil
}

Wanessa Debôrtoli de Miranda ${ }^{1}$

Iara Veloso Oliveira Figueiredo ${ }^{2}$

Mônica Silva Monteiro de Castro ${ }^{3}$

Fausto Pereira dos Santos ${ }^{4}$

Helvécio Miranda Magalhaes Junior ${ }^{5}$

Rômulo Paes de Sousa ${ }^{6}$

\begin{abstract}
Resumo
Objetivo: impacto da judicialização da saúde em diversas partes do mundo aponta para uma encruzilhada entre diversas formas de lidar com o fenômeno, em razão disso, o objetivo é contribuir para esse debate a partir de um panorama da judicialização no Brasil e um comparativo com experiências de outros países. Metodologia: tratou-se de revisão narrativa sobre o tema da judicialização da saúde em perspectiva comparada. A pesquisa foi dividida em duas etapas: contextualização da judicialização da saúde no cenário internacional, utilizando método comparativo na perspectiva do Direito Comparado, e a revisão narrativa sobre a judicialização da saúde no Brasil. Foram utilizados 46 trabalhos: 19 internacionais e 27 brasileiros. Resultados: duas abordagens diferentes para a judicialização da saúde se destacam nos estudos comparativos: a latino-americana e a sul-africana. Na primeira, o fenômeno apresenta maior magnitude com as decisões privilegiando o mínimo existencial, é especialmente complexo no Brasil, Colômbia e Costa Rica; na segunda a reserva do possível se sobressai nas decisões. A análise dos trabalhos realizados no Brasil subsidiou a construção de uma linha do tempo, proporcionando um panorama geral da judicialização no Brasil, e a trajetória desse fenômeno fluido, que se modificou ao longo do tempo à medida que novas problemáticas e formas de lidar foram surgindo e se desenvolvendo. Conclusões: o estudo evidencia que a judicialização da saúde é um fenômeno multifacetado, trazendo à tona um dilema entre vários caminhos a seguir. Porém, é um tema carente de estudos sobre o ponto de vista do usuário e dos desfechos sanitários decorrentes das ações judiciais. A complexidade do fenômeno culmina na diversidade de intervenções nos países, gerando conflitos entre garantir o direito à saúde e limitações orçamentárias.
\end{abstract}

\footnotetext{
${ }^{1}$ Doutora em Saúde Coletiva; nutricionista; professora adjunta, Departamento de Gestão em Saúde, Escola de Enfermagem, Universidade Federal de Minas Gerais. Belo Horizonte, Minas Gerais, Brasil. https://orcid.org/0000-00020838-9861. E-mail: wanessa.debortoli@hotmail.com

2 Mestre em Saúde Pública; advogada; doutoranda em Saúde Coletiva, Instituto Renê Rachou, Fiocruz Minas, Belo Horizonte, MG, Brasil. https://orcid.org/0000-0002-0927-859X. E-mail: iaravof@gmail.com

${ }^{3}$ Doutora em Saúde Pública; médica; pesquisadora, Instituto Renê Rachou, Fiocruz Minas, Belo Horizonte, MG, Brasil. https://orcid.org/0000-0003-2461-3699. E-mail: monica.castro@fiocruz.br

${ }^{4}$ Doutor em Saúde Coletiva; médico; pesquisador, Instituto Renê Rachou, Fiocruz Minas, Belo Horizonte, MG, Brasil. https://orcid.org/0000-0001-7100-6918. E-mail: fausto.pereira@fiocruz.br

${ }^{5}$ Doutor em Saúde Coletiva; médico; pesquisador, Instituto Renê Rachou, Fiocruz Minas, Belo Horizonte, MG, Brasil. https://orcid.org/0000-0002-7628-7509. E-mail: helveciomiranda@gmail.com

${ }^{6}$ Doutor em Epidemiologia Ambiental; médico; pesquisador sênior, Instituto Renê Rachou, Fiocruz Minas, Belo Horizonte, MG, Brasil. https://orcid.org/0000-0002-3384-6657. E-mail: romulo.paes@fiocruz.br
} 


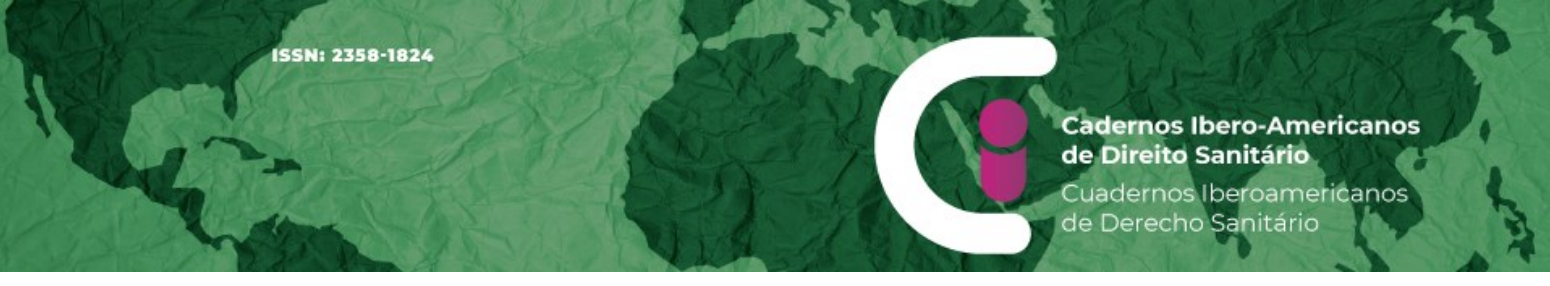

Conclui-se que a judicialização tem pontos positivos e negativos: ela é solução, mas também é problema.

\title{
Palavras-chave
}

Judicialização da saúde. Direito à saúde. Estudo comparativo.

\begin{abstract}
Objective: the impact of the judicialization of health in various parts of the world points to a crossroads between diverse ways of dealing with the phenomenon, therefore, the work aims to contribute to this debate from an overview of judicialization in Brazil and a comparison with experiences from other countries. Methodology: this was a narrative review on the theme of the judicialization of health in a comparative perspective. The research was divided into two stages: contextualization of the judicialization of health in the international scenario, using a comparative method from the perspective of Comparative Law, and a narrative review on the judicialization of health in Brazil. Forty-six works were used: 19 international and 27 Brazilian. Results: two different approaches to the judicialization of health stand out in comparative studies: the Latin American and the South African. In the first, the phenomenon presents greater magnitude with decisions favoring the minimum existential, it is especially complex in Brazil, Colombia, and Costa Rica; in the second, the reserve of the possible stands out in the decisions. The analysis of the work conducted in Brazil supported the construction of a timeline providing an overview of judicialization in Brazil, and the trajectory of this fluid phenomenon, which changed over time as new issues and ways of dealing with it emerged and developing. Conclusions: the study shows that the judicialization of health is a multifaceted phenomenon, bringing to light a dilemma between several paths to be followed. However, it is a subject that lacks studies on the user's point of view, and on the health outcomes resulted from lawsuits. The complexity of the phenomenon culminates in the diversity of interventions in countries, generating conflicts between guaranteeing the right to health and budgetary limitations. It is concluded that judicialization has positive and negative points: it is a solution, but it is also a problem.
\end{abstract}

\section{Keywords}

Judicialization of health. Right to health. Comparative study.

\section{Resumen}

Objetivo: el impacto de la judicialización de la salud en diferentes partes del mundo apunta a una encrucijada entre diferentes formas de abordar el fenómeno, por lo que el trabajo tiene como objetivo contribuir a este debate desde un panorama de la judicialización en Brasil y una comparación con experiencias. de otros países Metodología: se trató de una revisión narrativa sobre el tema de la judicialización de la salud en perspectiva comparada. La investigación se dividió en dos etapas: la contextualización de la judicialización de la salud en el escenario internacional, utilizando un método comparativo desde la perspectiva del Derecho Comparado, y la revisión narrativa sobre la judicialización de la salud en Brasil. Se utilizaron 46 obras: 19 internacionales y 27 brasileñas. Resultados: en los estudios comparados se destacan dos enfoques distintos de la judicialización de la salud: el latinoamericano y el sudafricano. En el primero, el fenómeno presenta mayor magnitud con decisiones a favor del mínimo existencial, es especialmente complejo en Brasil, Colombia y Costa Rica; en el segundo, la reserva de lo posible se destaca en las decisiones. El análisis del trabajo realizado en Brasil apoyó la construcción de un cronograma que brinde un panorama de la judicialización en Brasil, y la trayectoria de este fenómeno fluido, que cambió con el tiempo a medida que surgían y se desarrollaban nuevos temas y formas de abordarlo. Conclusiones: el estudio muestra que la judicialización de la salud es un fenómeno 
multifacético, que saca a la luz un dilema entre varios caminos a seguir. Sin embargo, es un tema que carece de estudios sobre el punto de vista del usuario y sobre los resultados de salud derivados de los juicios. La complejidad del fenómeno culmina en la diversidad de intervenciones en los países, generando conflictos entre la garantía del derecho a la salud y las limitaciones presupuestarias. Se concluye que la judicialización tiene puntos positivos y negativos; es una solución, pero también es un problema.

\section{Palabras clave}

Judicialización de la salud. Derecho a la Salud. Estudio comparativo.

\section{Introdução}

A saúde passou a ser considerada um direito inerente à condição humana a partir da Declaração Universal dos Direitos Humanos, em 1948. Desde aquele momento, países de todo mundo começaram a inserir o direito à saúde em suas constituições e em suas políticas de proteção social e de segurança humana. O Brasil é um dos cerca de cem países em que a Constituição considera saúde um direito, seja ele universal ou não (1). Entretanto, apenas a inserção do direito à saúde nos documentos constitucionais não garante a sua efetivação plena (2).

Em diversas partes do mundo, observa-se que os sistemas de saúde - especialmente aqueles segmentados em públicos e privados, como os dos Estados Unidos, Brasil e Argentina - apresentam limitações na garantia do direito à saúde. O distanciamento entre o direito constitucionalmente garantido e aquele que é de fato realizado é um dos determinantes da judicialização da saúde, quando diversos grupos da sociedade buscam a garantia do direito à saúde por meio do Poder Judiciário (3).

O termo judicialização surgiu na Itália em 1992, durante um seminário no Centro de Estudos do Poder Judiciário da Bolonha. Em 1995, Chester Neal Tate e Torbjörn Vallinder publicaram o livro The Global Expansion of Judicial Power, que consagrou o termo judicialização (4). No campo da saúde, Mapelli Júnior (5) define a judicialização como um incremento gradual e significativo de ações judiciais para a obtenção, por meio do Poder Judiciário, de medicamentos, insumos e outros produtos de interesse da saúde. Campilongo (6) define a judicialização da saúde como a reivindicação da saúde como um direito, que decorre das decisões coletivamente vinculantes tomadas pelo Poder Judiciário, as quais se sobrepõem ao arcabouço normativo do Sistema Único de Saúde (SUS). Já Tate e Vallinder (7) acreditam ser a judicialização uma reação do Judiciário, quando provocado por um terceiro, com o propósito de retificar decisão de um poder político realizada com fundamento na Constituição. 
No Brasil, de 2008 a 2017, houve um crescimento de aproximadamente $130 \%$ no número de ações judiciais de primeira instância que versam sobre o direito à saúde (8). Segundo Schulze (9), por meio da análise do relatório Justiça em Números, no ano de 2019 a judicialização da saúde seguiu aumentando, dando continuidade ao padrão de aumento observado nos relatórios dos anos anteriores. Schulze (9) acredita que, após a pandemia da COVID-19 em 2020, a tendência é a judicialização da saúde continuar aumentando, em razão de procedimentos eletivos que foram adiados e ampliação de demandas por outros serviços, como os de saúde mental.

Apesar do reconhecido papel da judicialização na garantia do direito, possibilitando o aumento de acesso a bens e serviços de saúde, seus desdobramentos podem promover consequências negativas para a gestão em saúde. Para o SUS, a judicialização leva a impactos importantes, tanto para o acesso às políticas públicas quanto para seu financiamento, visto que o deferimento de pedidos de prestação de serviços de saúde, incluindo medicamentos e insumos, pode desestruturar o planejamento e as políticas de saúde e privilegiar interesses individuais em detrimento do coletivo (10). Na esfera privada, as principais consequências são a alteração das relações contratuais entre clientes, operadoras e prestadores de serviços de assistência à saúde (8).

Pode-se afirmar que estamos diante de uma encruzilhada: seria a judicialização da saúde uma solução ou um problema? Nesse contexto, este artigo tem por objetivo contribuir para o debate, trazendo elementos da literatura especializada sobre o fenômeno da judicialização na perspectiva do Direito Comparado no Brasil e no mundo e buscando identificar lacunas de conhecimento sobre o tema.

\section{Metodologia}

Tratou-se de revisão narrativa sobre o tema da judicialização da saúde em perspectiva comparada. A revisão narrativa é o método apropriado para estudos que descrevem e discutem o estado da arte, sob um enfoque teórico (11) e permite que o tema seja discutido de forma ampla (12). Essa revisão proporciona ao leitor a visualização do conhecimento produzido em determinada área em curto espaço de tempo (11). Ela tem por característica a não utilização de critérios explícitos e sistemáticos ao se fazer a busca e análise crítica da literatura (12).

Para tanto, a pesquisa foi dividida em duas etapas. Na primeira, utilizou-se o método comparativo que, segundo Fachin (13), "consiste em investigar coisas ou fatos segundo suas 
semelhanças e diferenças". Assim, buscou-se na literatura a contextualização da judicialização da saúde no cenário internacional, na perspectiva do Direito Comparado. Duarte (14) afirma ser o Direito Comparado uma comparação de ordens jurídicas diversas. Cardoso (15) diz ser o desenvolvimento de abordagens contextualizadas de problemas comuns a vários sistemas jurídicos. O método do Direito Comparado permite a obtenção de dados relevantes para aprimoramento de direitos e de instrumentos jurídicos (16). Assim, os achados da literatura internacional, que totalizaram 19 trabalhos sobre judicialização da saúde, permitiram a observação e comparação desse fenômeno em cinco países (África do Sul, Costa Rica, Brasil, Colômbia e Argentina), que são os países sobre os quais encontramos maior discussão na literatura sobre o assunto. A observação foi realizada no contexto qualitativo da judicialização, uma vez que o presente trabalho não pretendeu esgotar a comparação da judicialização em todos os seus aspectos, o que certamente exigiria explorar a adoção de modelos diferentes de sistemas de saúde, assim como o financiamento e estrutura de serviços de saúde dos diferentes países.

Na segunda etapa, foi realizada uma revisão da literatura, na qual foram selecionados trabalhos sobre a judicialização da saúde no Brasil. Pela leitura de artigos encontrados por revisão narrativa (13), foram incluídos os artigos que abordaram a discussão da judicialização da saúde no Brasil na perspectiva dos seus marcos históricos e principais discussões. Foram utilizadas as seguintes bases de dados: Literatura Latino-Americana e do Caribe em Ciências da Saúde (LILACS) e Scientific Electronic Library Online (SciELO). Totalizaram 27 artigos que proporcionaram uma visão geral do fenômeno e ampararam a construção de uma linha do tempo sobre a judicialização da saúde no Brasil.

O presente artigo utilizou o arcabouço de 46 estudos (19 sobre a judicialização na perspectiva internacional; e 27 sobre a judicialização da saúde no Brasil) para a discussão do fenômeno. Essa foi a melhor estratégia encontrada para a pesquisa desenvolvida, visto que inicialmente tentou-se a realização de uma revisão sistemática da literatura, mas notouse uma grande pulverização de publicações sobre o tema, tanto no campo da saúde quanto no do direito e, por isso, muitas publicações importantes e já conhecidas não seriam incluídas na discussão. Optou-se, então, pela revisão narrativa, para abranger publicações importantes sobre a judicialização em um cenário internacional e no Brasil. 
Ngwena, R. Escopo e limite da judicialização do direito constitucional à saúde na África do Sul: avaliação de casos com referência específica à África do Sul Analisar a extensão da judicialização do direito constitucional à saúde na África justiciabilidade da saúde. Dir. sanit., São Paulo, v. 14, n. 2, p. 43-87, jul./out. 2013.

Vidal J, Di Fabio JL. Judicialización y acceso a tecnologías sanitarias: oportunidades y riesgos. Rev Panam Salud Publica. 2017;41:e137. doi: 10.26633/RPSP.2017.137

Reveiz L, Chapman E, Torres R, Fitzgerald J, Mendoza A, BM, et al. Litigios por derecho a la salud en tres países de América Latina: revisión sistemática de la literatura. Revista Panamericana de Salud Pública. 2013; 33(3): p. 213-222.

Nieto E, Arango A. Costos de los servicios de salud tutelados y del proceso legal de las tutelas en Medellín, 2009. Rev Fac Nac Colômbia Brasil, Colômbia, Costa Rica do Sul, considerando a possibilidade de interpretação judicial e aplicação prática.

Salud Publica. 2011;29(3):22331.

Machado MA, Acurcio F de A, Brandão CM, Faleiros DR, Guerra AA, Cherchiglia ML, et al. Judicialization of access to Brasil, Colômbia, Costa Rica

Contextualizar a evolução do fenômeno em relação aos instrumentos, mecanismos e procedimentos habitualmente utilizados pelas autoridades de saúde para racionalizar o acesso às tecnologias de saúde.

medicines in Minas Gerais state, Southeastern Brazil. Rev Saude Publica. 2011;45(3):590-8. 32. Marques SB, Dallari SG. Garantia do direito social à assistência farmacêutica no Estado de São Paulo. Rev Saude Publica. 2007;41(1): 101-7.

Pepe VL, Ventura M, Sant'ana JM, Figueiredo TA, Souza Vdos $R$, Simas L, Osorio-de-Castro CG. Caracterização de demandas judiciais de fornecimento de medicamentos "essenciais" no Estado do Rio de Janeiro, Brasil. Cad Saude

Publica. 2010;26(3):461-71.

Identificar e avaliar estudos que analisaram as características do contencioso por direito à saúde no Brasil, Colômbia e Costa Rica.

Reconstituir o percurso jurídico dos recursos de tutela dos direitos constitucionais, que envolvem os serviços de saúde, e determinar o custo de tais processos e dos serviços de saúde invocados em amostra de tais medidas proferidas na cidade de Medellín.

Analisar ações judiciais com demandas de acesso a medicamentos, no período de julho de 2005 a junho de 2006, no estado de Minas Gerais.

Analisar como o Poder Judiciário vem garantindo o direito social à assistência farmacêutica e qual a relação do sistema jurídico e político na garantia a esse direito.

Pesquisar as demandas de medicamentos considerados essenciais nas decisões da $2^{\mathrm{a}}$ instância do Tribunal de Justiça do Estado do Rio de Janeiro, Brasil, em 2006. 


\begin{tabular}{|c|c|c|}
\hline $\begin{array}{l}\text { Loaiza, O. R.; Morales, M.; } \\
\text { Norheim, O. F.; Wilson, B. M. } \\
\text { Revisiting Health Rights Litigation } \\
\text { and Access to Medications in } \\
\text { Costa Rica: Preliminary Evidence } \\
\text { from the Cochrane Collaboration } \\
\text { Reform. Judicial enforcement of } \\
\text { health rights: focus on latin } \\
\text { America. 2018; } 20(1): 79-91 .\end{array}$ & Costa Rica & $\begin{array}{l}\text { Examinar a tomada de decisão } \\
\text { reformada do tribunal para determinar } \\
\text { se o aumento da confiança na perícia } \\
\text { médica mudou os direitos de saúde } \\
\text { jurisprudência. }\end{array}$ \\
\hline $\begin{array}{l}\text { Chapman AR, Forman L, } \\
\text { Lamprea E. 2015. Evaluating } \\
\text { essential health packages from a } \\
\text { human rights perspective. J. } \\
\text { Hum. Rights 16:142-59. }\end{array}$ & Países em geral & $\begin{array}{l}\text { Avaliar os princípios a partir dos quais } \\
\text { os planos são desenvolvidos, o } \\
\text { conteúdo dos pacotes e a experiência } \\
\text { dos países que buscam implementá-los } \\
\text { a partir de uma perspectiva de direitos } \\
\text { humanos. Nesse processo, busca obter } \\
\text { maior clareza sobre as exigências dos } \\
\text { serviços de saúde em relação ao direito } \\
\text { à saúde. }\end{array}$ \\
\hline $\begin{array}{l}\text { Nakamura, F. C.; Caobianco, N. } \\
\text { M. A Judicialização do Direito à } \\
\text { saúde em uma perspectiva } \\
\text { comparada: Brasil e Colômbia. } \\
\text { Revista de Direito Sanitário. } \\
2019 .\end{array}$ & Brasil e Colômbia & $\begin{array}{l}\text { Estudar, em perspectiva comparada, a } \\
\text { judicialização da saúde no Brasil e na } \\
\text { Colômbia. }\end{array}$ \\
\hline $\begin{array}{l}\text { Zaring D. 2004. National } \\
\text { rulemaking through trial courts: } \\
\text { the big case and institutional } \\
\text { reform. UCLA Law Rev. 51:1015- } \\
78 .\end{array}$ & EUA & $\begin{array}{l}\text { Reconceituar processos de reforma } \\
\text { institucional - grandes casos } \\
\text { envolvendo a reforma estrutural de } \\
\text { entidades governamentais locais, como } \\
\text { prisões e } \\
\text { autoridades habitacionais } \\
\end{array}$ \\
\hline $\begin{array}{l}\text { Gargarella R. 2011. Dialogic } \\
\text { justice in the enforcement of } \\
\text { social rights: some initial } \\
\text { arguments. See Yamin \& } \\
\text { Gloppen 2011, pp. 232-45. } \\
\end{array}$ & Brasil e Colômbia & $\begin{array}{l}\text { Discutir as potencialidades das Cortes } \\
\text { em promover os direitos sociais da } \\
\text { população }\end{array}$ \\
\hline $\begin{array}{l}\text { Defago, M. A. P.; Faúndes, J. M. } \\
\text { M. Conservative litigation against } \\
\text { sexual and reproductive } \\
\text { reproductive health policies in } \\
\text { Argentina. Reproductive Health } \\
\text { Matters } 2014 ; 22(44): 82-90 .\end{array}$ & Argentina & $\begin{array}{l}\text { Analisar as estratégias de contencioso } \\
\text { das ONGs conservadoras e como seu } \\
\text { uso dos tribunais na Argentina mudou } \\
\text { ao longo dos anos. }\end{array}$ \\
\hline $\begin{array}{l}\text { Oliveira MRM, Delduque MC, } \\
\text { Sousa MF, Mendonça AVM. } \\
\text { Mediation: a way to disjudialize } \\
\text { health. Temp Act Saúde Col } \\
\text { [Internet]. } 2016 .\end{array}$ & Brasil & $\begin{array}{l}\text { Analisar o direito à saúde como direito } \\
\text { fundamental inserto na Constituição do } \\
\text { país e ainda não executado plenamente } \\
\text { pelo Estado e discutir como as } \\
\text { demandas têm superlotado os Tribunais } \\
\text { de Justiça, provocando os gestores } \\
\text { públicos governamentais, no âmbito do } \\
\text { Sistema Único de Saúde }\end{array}$ \\
\hline
\end{tabular}

Fonte: elaborado pelos autores.

Em razão da presença dos direitos sociais nos textos constitucionais, observa-se a tendência de exigibilidade judicial dos direitos sociais por magistrados que, ao emitirem as 
decisões, costumam invocar a universalidade do sistema público e obrigação de fazer aos entes estatais. Tais decisões colidem com o planejamento político e orçamentário e a escassez dos recursos, que são alocados para programas que constituem as políticas públicas (5).

A materialização do direito social à saúde pela via judicial traz à luz o confronto entre as teorias da reserva do possível e do mínimo existencial. A garantia do mínimo existencial, que obriga o Estado a prestações que criem condições materiais mínimas para uma vida digna dos seus cidadãos, está embasada no princípio da dignidade humana, no direito à vida e à integridade física e no direito geral de liberdade (18). Já a teoria da reserva do possível subdivide-se em reserva do possível fática, que é inexistência de fato dos recursos, ou seja, o vazio dos cofres públicos; e em reserva do possível jurídica, que é a ausência de autorização para que determinado gasto seja realizado (19). É muito usada como pressuposto para justificar a inviabilidade econômica de o Estado prestar certos serviços (20).

Para Araújo et al. (20), a judicialização da saúde para a garantia do mínimo existencial não é possível em sua completude, tendo em vista a reserva do possível, frequentemente invocada pelo Poder Público. O enfoque fático da reserva do possível é uma questão intrinsecamente associada à insuficiência de recursos, também denominada reserva do financeiramente possível. Os autores chamam a atenção, porém, para o fato de que a teoria da reserva do possível não pode ser utilizada como forma de legitimar a omissão do Estado em relação aos direitos e necessidades dos que dele necessitam, para ver saciadas as suas necessidades básicas, como é no caso do acesso à saúde, consequentemente preservando o direito à vida.

Brinks e Gauri (21) colocam em questão a possibilidade do deslocamento da política da arena legislativa para a arena judicial, diante do fato de a constitucionalização de direitos sociais e econômicos sem o seu cumprimento simplesmente aprofundar a má distribuição de recursos existente e do acesso aos benefícios fornecidos pelo Estado, e se é possível por meio da judicialização diminuir, de alguma forma, essa desigualdade. O dilema compartilhado pelos países que se propõem a construir um modelo universal e gratuito de saúde é claro: os recursos orçamentários são limitados e os custos da tecnologia na saúde nem sempre podem ser sustentados. A ingerência do Judiciário, a partir de decisões que determinam prestações positivas em saúde, agrava ainda mais a tensão entre a escassez de recursos e os elevados custos das tecnologias no campo da saúde (5). 
Assim, a capacidade da judicialização da saúde de promover sistemas de saúde mais equitativos é um dos grandes questionamentos da atualidade. Possivelmente, enquanto o Judiciário se dedicar a atender às reivindicações de necessidades ou desejos individuais daqueles que têm acesso ao Judiciário, o desafio da construção de um sistema de saúde público, universal e equitativo estará cada vez mais distante de se efetivar, eo direito humano à saúde continuará no horizonte como algo inalcançável.

\section{O surgimento e a contextualização da judicialização da saúde}

Os pareceres judiciais pioneiros sobre a aplicabilidade do direito à saúde datam da década de 1990 e do início dos anos 2000, abordando o tratamento para a epidemia de HIVIAIDS $(22,23)$. Durante esse período, os tribunais superiores de doze países ${ }^{7}$ de média e baixa renda proferiram vários julgamentos históricos sobre o acesso à terapia antirretroviral (24).

A literatura internacional explora muito pouco o fenômeno da judicialização. Diante da verificação dessa escassez de estudos, Leitão et al. (9) questionam se a judicialização, em especial a da assistência farmacêutica, é um problema específico dos países em desenvolvimento, com maior evidência no cenário da saúde pública brasileira, ou se tal carência de estudos específicos deve-se à omissão científica, considerando que nações de todo o mundo estão expostas a tais complicações político-estruturais.

Duas abordagens diferentes para a judicialização da saúde vêm ganhando destaque na discussão de estudos comparativos, a sul-africana e a latino-americana, apresentando caminhos divergentes para o litígio e a execução judicial do direito à saúde. A diferença mais importante entre essas duas abordagens é que o limiar para defender e apresentar reivindicações baseadas em direitos na África do Sul é muito mais alto do que em países da América Latina, como Brasil, Colômbia e Costa Rica (21).

Ao analisar decisões dos tribunais em processos constitucionais envolvendo o direito à saúde na África do Sul pós-apartheid, verifica-se que a Corte Constitucional sul-africana mantém a cautela e, mesmo quando encontra violações a direitos, permanece consciente de suas limitações em termos de competências constitucionais e institucionais. Importante decisão judicial, que ficou conhecido como caso Soobramoney, pode ser usado para exemplificar essa realidade. Nesse caso, o requerente para o tratamento de diálise renal

\footnotetext{
${ }^{7}$ Argentina, Brasil, Bolívia, Colômbia, Costa Rica, Equador, Índia, Nigéria, Panamá, El Salvador, África do Sul e Venezuela.
} 
apresentava um quadro irreversível e não poderia, no longo prazo, ser um candidato ao transplante de rim, condição necessária para cumprir os critérios médicos para a diálise em hospitais públicos. O pedido foi indeferido pela Corte Constitucional, com a justificativa de escassez de recursos, alegada pelo Estado, para oferecer um tratamento prolongado, quando o setor público de saúde tem capacidade para atender apenas $30 \%$ da demanda por esse tipo de tratamento (25).

Essa é uma hipótese do porquê a judicialização da saúde na África do Sul ser muito menos difundida do que na América Latina, que concentra a maior parte dos processos de judicialização registrados no mundo (26). Nesse caso, diante do impasse entre mínimo existencial e a reserva do possível, a reserva do possível foi a ganhadora, o que não costuma acontecer com frequência nos países da América Latina.

Em revisão de literatura sobre o tema na Venezuela, Costa Rica e Brasil, Reveiz et al. (27) apontaram as limitações dos sistemas de saúde em atender as demandas da população, particularmente em relação à garantia de acesso a serviços incluídos nos sistemas de saúde e à incorporação de novas tecnologias sanitárias. Quanto à incorporação de novas tecnologias, estudos do Brasil e Colômbia destacaram que alguns dos medicamentos frequentemente reivindicados apresentavam uma alternativa terapêutica já incorporada no sistema de saúde e, em alguns casos, seria possível que o número significativo de ações judiciais de determinadas tecnologias em saúde tenha influenciado a decisão de incorporá-las (28-31).

Na Costa Rica, a judicialização da saúde começou a emergir lentamente em meados da década de 1990, expandindo-se rapidamente ao final daquela década, desencadeada por dois eventos: primeiro, a reforma judicial de 1989, que criou uma câmara constitucional do Supremo Tribunal Federal (a Sala IV), abrindo uma arena jurídica muito acessível; segundo, a incapacidade ou falta de vontade do sistema de saúde público em responder à epidemia de HIVIAIDS nos anos de 1990, o que levou os portadores desse agravo a usar o Tribunal recém-criado para procurar ajuda médica. Rapidamente a judicialização tornou-se um grande desafio, em que mais de $70 \%$ das decisões favoráveis do Tribunal foram de fornecimento de medicamentos de baixa prioridade, sugerindo uma falta de equidade no acesso a medicamentos (32).

Diante do grande aumento da judicialização da saúde, que constituía uma ameaça à sobrevivência financeira do sistema de saúde estatal, a Costa Rica iniciou, em 2014, uma parceria com a Cochrane Collaboration para incorporar avaliações de especialistas em seu 
processo de tomada de decisões para acesso a medicamentos. Tal medida, segundo Loaiza et al. (32), reduziu a porcentagem de decisões que concedem medicamentos experimentais, enquanto a porcentagem de concessão de medicamentos de alta prioridade aumentou, representando ganhos na busca pela equidade.

Na Colômbia, o considerável aumento da judicialização é atribuído a duas instituições judiciais introduzidas pela Constituição de 1991, que diminuíram o limiar para levar reivindicações baseadas em direitos aos tribunais. A via rápida - o procedimento barato $\mathrm{e}$ que apresenta taxas de sucesso em favor dos reclamantes de quase $80 \%$ - permitiu que milhares de pessoas obtivessem respostas judiciais rápidas dos tribunais locais e superiores às suas demandas por serviços de saúde, sem o envolvimento de advogados ou honorários (23).

O Tribunal Constitucional colombiano vem investindo esforços para controlar os litígios sobre direitos à saúde. Em 2008, o Tribunal colombiano emitiu um parecer (T-760) para implementação de medidas regulatórias destinadas a corrigir os incentivos institucionais que estavam impulsionando a onda de litígios. Esse parecer apresentou um total de 32 pedidos, dentre eles, 16 ordenando que várias empresas de seguros de saúde prestassem os serviços exigidos pelos 22 demandantes individuais que entraram com os processos, e 16 pedidos endereçados ao Ministério da Saúde e outras agências reguladoras. Convergindo com o parecer T-760, o Tribunal colombiano instituiu um mecanismo de acompanhamento para avaliar a conformidade do governo com as ordens do tribunal e organizou duas audiências públicas em 2011 e 2012 (33, 23).

Em 2015, o Congresso da Colômbia instituiu a Lei $\mathrm{n}^{\circ}$ 1.751, determinando a elaboração de um plano de benefícios de saúde, com um conjunto de medicamentos e tratamentos não cobertos pelo sistema de saúde, ao invés de uma lista detalhada de tratamentos e medicamentos obrigatórios. De acordo com os formuladores da lei, esse novo plano de benefícios deveria coibir litígios por medicamentos e tratamentos estranhos ao sistema de saúde (34).

Os sistemas colombiano e brasileiro têm estruturas principiológicas semelhantes, mesmo que na Colômbia o caminho para a integralidade e universalidade seja mais demorado (35). O uso de audiências públicas, tanto na Colômbia quanto no Brasil, são exemplos de um modelo multilateralista de concessão, no qual o juiz não é o ator principal ou único, mas há uma rede de atores que interage no processo, representando uma instância de ativismo judicial dialógico $(36,37)$. 
Outros países apresentam estratégias interessantes para intervir no aumento de judicialização da saúde. Nos últimos dez anos, a Argentina registrou um aumento de litígios relacionados a direitos sexuais e reprodutivos. No país, organizações não-governamentais (ONGs) conservadoras - movidas por uma moralidade sexual restritiva contra métodos contraceptivos e políticas de saúde reprodutiva e opondo-se ao aborto - vêm movendo ações recorrentes na justiça. Em março de 2012, o Supremo Tribunal Nacional de Justiça proferiu uma decisão esclarecendo o escopo do termo aborto não punível (aborto legalmente admissível ou não punível), e determinou que as províncias do país desenvolvessem regulamentos legais sobre o aborto, a fim de evitar futuros processos e garantir o acesso ao procedimento (38).

Ao se falar em saúde e fazer comparações, é importante considerar que cada país apresenta suas particularidades em relação à adoção de modelos de saúde: variação dos gastos de dólar por habitante com saúde, quantidade de leitos por habitantes, entre outros fatores que os diferenciam. Por exemplo, enquanto na Colômbia está em vigência um sistema de asseguramento com contingenciamento de cobertura, segmentação dos usuários com pagamento de taxas de acordo com a capacidade financeira, no Brasil apresenta-se um sistema nacional de saúde público com financiamento proveniente dos tributos e impostos. O SUS é financiado por todos os cidadãos (35).

É importante lembrar que também há diferenciações na forma de solução dos conflitos pelas Cortes Constitucionais dos países. Porém, o ponto em comum é, como apresentado por Nakamura e Caobianco (35), a tensão entre os poderes Executivo, Legislativo e Judiciário, com questionamentos sobre os limites de atuação da Corte Constitucional nas políticas de saúde e o estabelecimento de várias formas de ativismo judicial.

Em regra, a maioria dos países da América Latina, exceto o Brasil, apresentam na saúde novos modelos com a adoção da política de mercado e incentivo à participação privada, caracterizados pela descentralização e diminuição da atuação do Estado e dos serviços públicos. Entretanto, mesmo heterogêneos, os países latino-americanos se aproximam por fatores sociais, políticos e históricos (35).

No Brasil, a judicialização da saúde também se iniciou com as ações de medicamentos para a AIDS. Posteriormente, as demandas judiciais sobre a AIDS diminuíram em razão da perda de objeto, pois entrou em vigor uma lei que previa distribuição gratuita e universal dos antirretrovirais. Porém, abriu-se o precedente de recorrer ao Judiciário para prestações em saúde, o que impulsionou um aumento das ações judiciais de 
todos os tipos de prestações em saúde (39), e fez com que a judicialização da saúde crescesse exponencialmente, especialmente em anos mais recentes.

\section{A judicialização da saúde no Brasil}

A Constituição da República Federativa do Brasil de 1988 (CRFB) representa um marco na normatização e no reconhecimento da saúde enquanto direito de cidadania, cujo provimento, a partir da consolidação do SUS, passou a ser de responsabilidade do Estado, por meio do art. 196. A saúde como direito, aliada ao princípio da inafastabilidade de jurisdição, prevista no art.5 $5^{\circ}, \mathrm{XXXV}$ da CRFB, que declara que "a lei não excluirá da apreciação do Poder Judiciário lesão ou ameaça a direito" são os pilares da judicialização da saúde brasileira (40).

No país, o marco inicial da judicialização da saúde foram as demandas para acesso aos medicamentos antirretrovirais, que resultou na promulgação da Lei n 9.313/96 (Figura 1). Além das ações individuais, uma estratégia judicial utilizada naquele momento foram as ações coletivas. Porém, tais ações coletivas foram aos poucos deixando de ter destaque no Judiciário, dando lugar ao grande aumento de ações individuais (41).

Figura 1. Linha do tempo de marcos da evolução da judicialização da saúde no Brasil

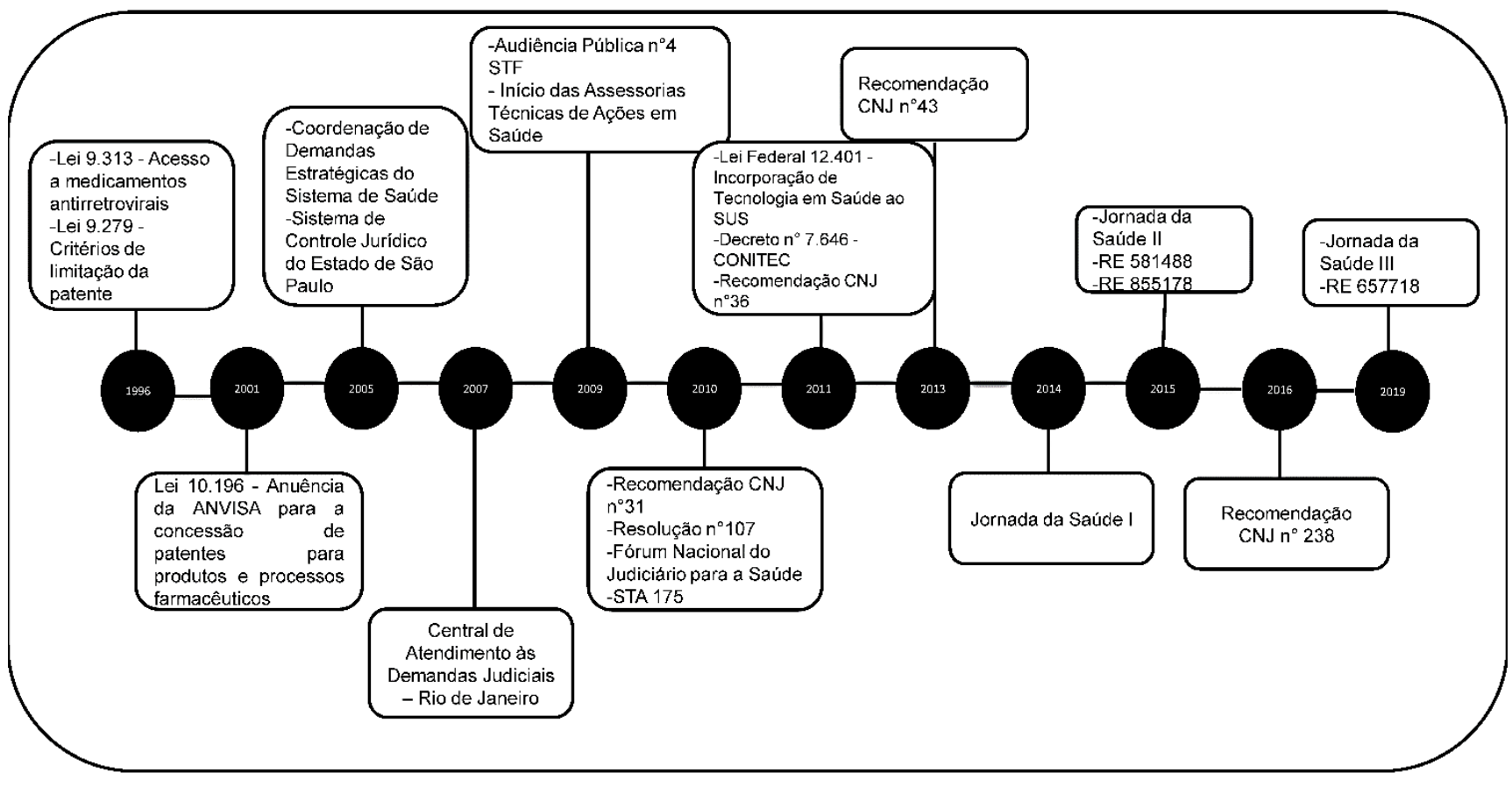

Fonte: elaborado pelos autores a partir da revisão de literatura. 
Na Figura 1, estão apresentados alguns dos marcos da judicialização da saúde no Brasil, a partir de 1996. É possível observar que, a partir dos anos 2000, foram mobilizados diferentes poderes e instâncias, estabelecendo-se relações Judiciário-Executivo muito mais intensas e cooperativas do que em seu início (42).

Alguns dos determinantes no período foram: o surgimento de novos medicamentos ainda não incorporados pelo governo federal ao SUS; conflitos de interesse com a indústria farmacêutica que, em certa medida, usa da judicialização para promover uma espécie de incorporação paralela de tecnologias, garantindo o financiamento público para tecnologias que não apresentam as condições necessárias para a incorporação regular; o padrão do Judiciário em deferir pedidos sem considerar as evidências científicas; e os potenciais impactos orçamentários em suas decisões. Como resposta a um dos determinantes da judicialização, buscou-se organizar a incorporação de novas tecnologias por meio da criação da Comissão Nacional de Incorporação de Tecnologias do SUS (CONITEC) (43), e aumentar a informação técnica disponível aos magistrados por meio dos Núcleos de Assessoria Técnica (NATs) nos tribunais estaduais.

Os Poderes Executivos estaduais também investiram em estratégias importantes, tais como a criação, em 2005, da Coordenação de Demandas Estratégicas do Sistema de Saúde no estado de São Paulo (Codes-SP) e do Sistema de Controle Jurídico do estado de São Paulo (SCJ-SP) e, em 2007, da Central de Atendimento às Demandas Judiciais (CADJ) no Rio de Janeiro (Figura 1).

Vários estados buscaram fazer soluções administrativas de resolução de conflito: ofício direto da Defensoria, grupos de solução administrativa, melhora da resposta ao sistema de Justiça, articulação interna com as Procuradorias e implementação de serviços de Assistência Farmacêutica, no caso dos medicamentos.

A partir de 2009, o debate sobre o tema foi intensificado, com a convocação pelo STF da Audiência Pública $n^{\circ} 4$, em razão da percepção de que a judicialização da saúde estava excessiva, e da necessidade de encontrar critérios mais técnicos para as decisões do Judiciário em matéria de saúde (44). Essa audiência foi um marco na judicialização da saúde, e a partir dela foi publicada a Recomendação do Conselho Nacional de Justiça (CNJ) $n^{\circ}$ 31/2010, que versou sobre o apoio técnico para o Judiciário incentivar a criação dos Núcleos de Assessorias Técnicas (NATs) (45), sendo o Rio de Janeiro o primeiro estado a criar um NatJus como um projeto-piloto. A Resolução n 107/2010 instituiu o Fórum da Saúde para ampliar esforços em busca da efetividade dos processos judiciais e da prevenção de novos 
conflitos que envolvam a saúde pública e a privada (46). Além disso, o Fórum também realizou Jornadas de Direito da Saúde (45), em que foram discutidos e aprovados, entre os anos de 2014 a 2019, 103 enunciados - que são contribuições aos juízes sobre como conduzir o julgamento de questões de saúde.

Ao longo dos anos o STF se posicionou e firmou precedentes importantes sobre a temática. O primeiro grande julgado específico foi a Suspensão de Tutela Antecipada 175 (STA 175) em 2010, que deliberou sobre a obrigatoriedade de fornecimento de medicamento pelo SUS, e fixou parâmetros que influenciaram a jurisprudência a partir desse momento (47). Assim, vieram as três teses de Repercussão Geral em Recursos Extraordinários (RE): o RE 581488, que veda no SUS acomodação ou atendimento diferenciado mediante pagamento de diferenças; o RE 855178, de 2015, que dispõe sobre a solidariedade dos entes federados pelas prestações de saúde e competência da autoridade judicial de direcionar o cumprimento conforme as repartições de competência; e o RE 657718, de 2019, que desobriga o estado e fornecer medicamentos experimentais, sem registro na ANVISA, salvo exceções (48).

Mais recentemente, tem havido um movimento antagônico à judicialização, a desjudicialização da saúde, que utiliza estratégias extrajudiciais e de redução da judicialização, por meio da busca do diálogo entre o Executivo, os usuários, o Judiciário e os técnicos da saúde. É resultado da Audiência $\mathrm{n}^{\circ} 4$, que incentivou as iniciativas de autocomposição dos litígios. Na ocasião, o Comitê Interinstitucional de Resolução Administrativa de Demandas da Saúde (CIRADS) foi citado por dois ministros, como possível modelo para redução da judicialização da saúde (44). Apesar dos evidentes esforços de intervenção sobre os conflitos, o alcance dessas medidas foi limitado.

\section{Judicialização da saúde no Brasil: problema ou solução?}

A revisão de literatura possibilitou identificar que, no Brasil, são dominantes na produção acadêmica sobre esse tema os aspectos das implicações políticas, sociais, sanitárias, jurídicas, éticas, de gestão e de financiamento. Mais especificamente, são abordados a garantia de direitos, o acesso a medicamentos, os impactos sobre a gestão, o perfil dos demandantes e as possíveis iniquidades decorrentes (29, 49, 40, 51-54).

A literatura nacional aborda o fenômeno de forma polarizada (55). De um lado, há o entendimento de que a judicialização constitui-se em um empecilho para a efetivação do direito à saúde enquanto direito coletivo, promovendo acesso desigual ao SUS ao favorecer 


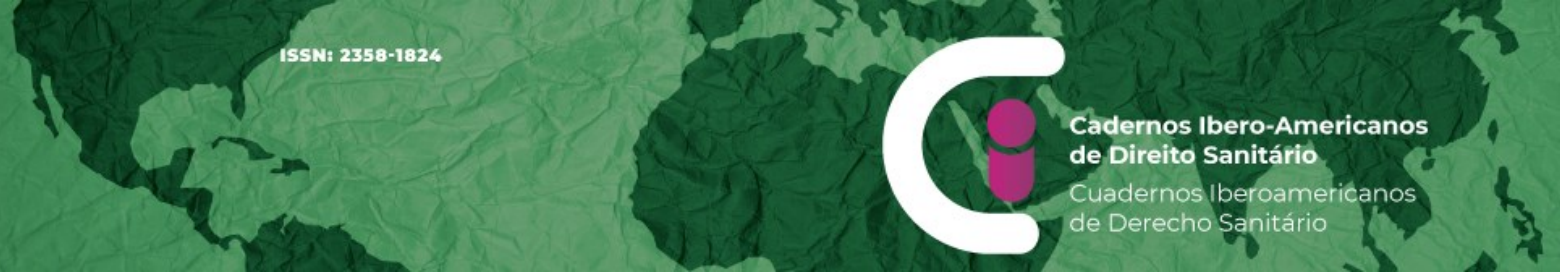

aqueles que acionam o Poder Judiciário e causando desequilíbrio na distribuição de competências dentro do sistema $(46,56,54)$. De outro lado, entende-se que esse fenômeno é um instrumento legítimo e eficaz para a efetivação do direito à saúde, universal e integral, previsto na Constituição, sendo um efeito da democracia $(52,57,58)$.

A literatura sobre o tema revela a complexidade e diversidade de motivos para a judicialização, as características dos litigantes e as consequências sobre as políticas de saúde pública e suplementar, em relação à oferta de serviços de assistência à saúde. Foram analisados 27 estudos sobre a judicialização da saúde no Brasil, sendo que a maior parte deles (37\%) foi realizada em São Paulo e Minas Gerais. Dentre os objetivos identificados, estão caracterizar a demanda, os litigantes e os elementos processuais que respaldam as decisões das demandas; os medicamentos demandados; as relações entre médico prescritor, advogado e indústria farmacêutica; a origem, o motivo, o objeto e a resolutividade das decisões judiciais; além de analisar o impacto da judicialização e o perfil do gasto da saúde pública (Quadro 2).

Quadro 2. Referência, local e objetivo dos estudos selecionados sobre a judicialização da saúde no Brasil

\begin{tabular}{|l|c|l|}
\hline \multicolumn{1}{|c|}{ Referência } & Estado & \multicolumn{1}{|c|}{ Objetivo do estudo } \\
\hline $\begin{array}{l}\text { Chieffi, A.L.; Barata, R.B. Judicialização da } \\
\text { política pública de assistência farmacêutica e } \\
\text { equidade. Cad de Saúde Pública. 2009; v. 25, p. } \\
\text { 1839-1849. }\end{array}$ & SP & $\begin{array}{l}\text { Caracterizar demandas judiciais para obter } \\
\text { medicamentos por meio do Departamento de } \\
\text { Saúde do Estado de São Paulo. }\end{array}$ \\
\hline $\begin{array}{l}\text { Pepe et al. Characterization of lawsuits for the } \\
\text { supply of" essential" medicines in the State of Rio } \\
\text { de Janeiro, Brazil. Cad de Saúde Pública. 2010; v. } \\
\text { 26, n. 3, p. 461-471. }\end{array}$ & RJ & $\begin{array}{l}\text { Pesquisar as demandas de medicamentos } \\
\text { considerados essenciais nas decisões da 2a } \\
\text { instância do Tribunal de Justiça do Estado do } \\
\text { Rio de Janeiro, Brasil, em 2006. }\end{array}$ \\
\hline $\begin{array}{l}\text { Chieffi, A.L.; Barata, R.C.B Ações judiciais: } \\
\text { estratégia da indústria farmacêutica para } \\
\text { introdução de novos medicamentos. Rev de } \\
\text { Saúde Pública. 2010; v. 44, n. 3, p. 421-429. }\end{array}$ & SP & $\begin{array}{l}\text { Analisar a concentração na distribuição dos } \\
\text { processos judiciais segundo medicamento } \\
\text { (fabricante), médico prescritor e advogado } \\
\text { impetrante da ação. }\end{array}$ \\
\hline $\begin{array}{l}\text { Sant'Ana et al. Rational therapeutics: health- } \\
\text { related elements in lawsuits demanding } \\
\text { medicines. Rev de Saúde Pública. 2011; v. 45, n. } \\
\text { 4, p. 714-721. }\end{array}$ & RJ & $\begin{array}{l}\text { Caracterizar os principais elementos } \\
\text { processuais, médico-científicos e sanitários } \\
\text { que respaldam as decisões das demandas } \\
\text { judiciais individuais por medicamentos } \\
\text { consideradas essenciais. }\end{array}$ \\
\hline $\begin{array}{l}\text { Machado et al. Judicialização do acesso a } \\
\text { medicamentos no Estado de Minas Gerais, Brasil } \\
\text { Rev de Saúde Pública. 2011; v. 45, p. 590-598. }\end{array}$ & MG & $\begin{array}{l}\text { Analisar o perfil dos requerentes e dos } \\
\text { medicamentos pleiteados em ações judiciais. }\end{array}$ \\
\hline $\begin{array}{l}\text { Neto et al. Médicos, advogados e indústria } \\
\text { farmacêutica na judicialização da saúde em Minas } \\
\text { Gerais, Brasil. Rev de Saúde Pública. 2012; v. 46, } \\
\text { p. 784-790. }\end{array}$ & MG & $\begin{array}{l}\text { Descrever as relações entre médico prescritor, } \\
\text { advogado e indústria farmacêutica em ações } \\
\text { judiciais contra o Estado. }\end{array}$ \\
\hline
\end{tabular}


Petean et al. Direito à saúde: demanda por suplementos no Tribunal de Justiça. Rev Eletr de Enfermagem. 2012; v. 14, n. 1, p. 68-76.

Souza et al. Direito à saúde no tribunal de justiça: demanda por medicações em oncologia. Rev da Rede de Enfermagem do Nordeste. 2012; v. 13, n. 4.

Stamford, A.; Cavalcanti, M. Decisões judiciais sobre acesso aos medicamentos em Pernambuco. Rev de Saúde Pública. 2012; v. 46, p. 791-799.

Medeiros, M.; Diniz, D.; Doederlein, S. A tese da judicialização da saúde pelas elites: os medicamentos para mucopolissacaridose. Ciência \& Saúde Coletiva. 2013 v. 18, n. 4.

Ramos, K.A.; Ferreira, A.S.D. Análise da demanda de medicamentos para uso off label por meio de ações judiciais na Secretaria de Estado de Saúde de Minas Gerais. Rev de Direito Sanitário. 2013; v. 14, n. 1, p. 98-121.

Provin, M.P.; Leite, S.N.; Amaral, R.G. Social inequalities in lawsuits for drugs. Brazilian Journal of Pharmaceutical Sciences 2013; v. 49, n. 3, p. 465-474.

Coelho et al. Variáveis jurídicas e de saúde no deferimento de liminares por medicamentos em Minas Gerais. Rev de Saúde Pública. 2014; v. 48, n. 5 , p. 808-816.

Gomes et al. Acesso aos procedimentos de média e alta complexidade no Sistema Único de Saúde: uma questão de judicialização. Cad de Saúde Pública. 2014; v. 30, p. 31-43.

Wang et al. Os impactos da judicialização da saúde no município de São Paulo: gasto público e organização federativa. Rev de Administração Pública-RAP. 2014; v. 48, n. 5.

Lopes et al. Medicamentos biológicos para o tratamento de psoríase em sistema público de saúde. Rev de Saúde Pública. 2014 v. 48, n. 4, p. 651-661.

Cabral, I.; Rezende, L.F. Análise das ações judiciais individuais para fornecimento de medicamentos em São João da Boa Vista. Rev de Direito Sanitário. 2015; v. 16, n. 1, p. 59-77.

Asensi et al. Judicialização, direito à saúde e prevenção. Rev Eletron de Comun Inf Inov Saúde. 2015 jan-mar; 9(1).

Pereira, J.G.; Pepe, V.L.E. Acesso a medicamentos por via judicial no Paraná: aplicação de um modelo metodológico para análise e monitoramento das demandas judiciais. Rev de Direito Sanitário. 2015; v. 15, n. 2, p. 3045.
Conhecer a origem, o motivo, o objeto, o MT sujeito demandante e a resolutividade das decisões judiciais.

Descrever a demanda do direito à saúde no

MT Tribunal de Justiça do estado de Mato Grosso sobre medicamentos para pessoas com câncer.

Analisar as decisões do sistema jurídico sobre acesso da população a medicamentos no

PE Sistema Único de Saúde por via judicial quanto a critérios de decisão e eventuais pressões políticas e econômicas.

Avaliar a hipótese de se a judicialização de medicamentos para 0 tratamento das mucopolissacaridoses no Brasil seria uma ação das elites econômicas.

Investigar a ocorrência de pedido judicial de medicamento para indicações não aprovadas MG pela Agência Nacional de Vigilância Sanitária, por meio de ações judiciais contra o estado de Minas Gerais no ano de 2010.

Caracterizar as ações judiciais que solicitaram

GO medicamentos considerando o perfil econômico de seus impetrantes.

MG

Investigar fatores relacionados ao deferimento de liminares por medicamentos.

Investigar as ações judiciais para acesso a procedimentos ambulatoriais e hospitalares do estado de Minas Gerais, Brasil, no período de 1999 a 2009.

Analisar o impacto da judicialização da saúde no município de São Paulo.

Analisar o acesso e o perfil de utilização, por via judicial, de medicamentos biológicos para o tratamento de psoríase.

Analisar as ações judiciais individuais SP realizadas para garantir o acesso a medicamentos no município de São João da Boa Vista -SP.

Analisar a prática da medicina preventiva, no RJ que concerne à vacinação, decorrente da intervenção do poder Judiciário.

Aplicar o modelo metodológico desenvolvido na análise das demandas judiciais individuais para o acesso a medicamentos no estado do Paraná. 


\begin{tabular}{|c|c|c|}
\hline $\begin{array}{l}\text { Massaú, G.C.; Bainy, A.K. O Impacto da } \\
\text { judicialização da saúde na comarca de Pelotas. } \\
\text { Rev de Direito Sanitário. 2015; v. 15, n. 2, p. 46- } \\
65 .\end{array}$ & RS & $\begin{array}{l}\text { Desvelar o impacto da judicialização da saú } \\
\text { na comarca de Pelotas. }\end{array}$ \\
\hline $\begin{array}{l}\text { Biehl, J.; Socal, M.P.; Amon J.J. The judicialization } \\
\text { of health and the quest for state accountability: } \\
\text { Evidence from } 1,262 \text { lawsuits for access to } \\
\text { medicines in Southern Brazil. Health and human } \\
\text { rights, 18(1), 209. (2016). }\end{array}$ & RS & $\begin{array}{l}\text { Avaliar as reivindicações e perfil das pessoas } \\
\text { apontando a heterogeneidade do fenômen } \\
\text { da judicialização. }\end{array}$ \\
\hline $\begin{array}{l}\text { Leitão et al. Análise das demandas judiciais para } \\
\text { aquisição de medicamentos no estado da Paraíba } \\
\text { Saúde e Sociedade. 2016; v. 25, p. 800-807. }\end{array}$ & PB & $\begin{array}{l}\text { Descrever os aspectos médico-científicos e } \\
\text { sanitários dos mandados judiciais para } \\
\text { fornecimento de medicamentos impetrados ao } \\
\text { Tribunal de Justiça da Paraíba contra agentes } \\
\text { públicos. }\end{array}$ \\
\hline $\begin{array}{l}\text { Nunes, C.F.O.; Ramos Jr, A.N. Judicialização do } \\
\text { direito à saúde na região Nordeste, Brasil: } \\
\text { dimensões e desafios. Cad. Saúde Colet., (Rio J.), } \\
\text { 2016. 24(2), 192-199. }\end{array}$ & CE & $\begin{array}{l}\text { Caracterizar a judicialização do direito à saúde } \\
\text { no estado do Ceará, dimensionar sua } \\
\text { magnitude e descrever o perfil dos sujeitos, } \\
\text { das patologias e dos objetos demandados. }\end{array}$ \\
\hline $\begin{array}{l}\text { Silva, E.; de Almeida, K.C.; Pessoa, G.S.C Análise } \\
\text { do gasto com judicialização de medicamentos no } \\
\text { Distrito Federal, Brasil. Cadernos Ibero- } \\
\text { Americanos de Direito Sanitário, 2017; 6(1), 112- } \\
126 .\end{array}$ & DF & $\begin{array}{l}\text { Analisar o perfil do gasto da saúde pública no } \\
\text { Distrito Federal com medicamentos não } \\
\text { padronizados }\end{array}$ \\
\hline $\begin{array}{l}\text { Arruda et al. Análise sobre a judicialização da } \\
\text { saúde no estado de Mato Grosso no período de } \\
2011-2012 \text {. Cad lbero-Americanos de Direito } \\
\text { Sanitário. 2017; v. 6, n. 1, p. 86-111. }\end{array}$ & MT & $\begin{array}{l}\text { Compreender o fenômeno da judicialização do } \\
\text { acesso à saúde pública no estado do Mato } \\
\text { Grosso. }\end{array}$ \\
\hline $\begin{array}{l}\text { Gomes O Erro médico sob o olhar do Judiciário: } \\
\text { uma investigação no Tribunal de Justiça do } \\
\text { Distrito Federal e Territórios. Cad. Ibero- } \\
\text { Americanos de Direito Sanitário. 2017; v. 6, n. 1, } \\
\text { p. 72-85. }\end{array}$ & DF & $\begin{array}{l}\text { Conhecer as decisões judiciais de segun } \\
\text { instância sobre o erro médico. }\end{array}$ \\
\hline $\begin{array}{l}\text { INSPER. Instituto de Ensino e } \text { Pesquisa. } \\
\text { Judicialização da saúde no Brasil: perfil das } \\
\text { demandas, causas e propostas de solução. } \\
\text { Conselho Nacional de Justiça. } 2019 \text {. }\end{array}$ & Nacional & $\begin{array}{l}\text { Analisar a representatividade nacional da } \\
\text { judicialização da saúde, com classificação que } \\
\text { identifique tipos de demandas e e } \\
\text { características das decisões judiciais. }\end{array}$ \\
\hline
\end{tabular}

Fonte: elaboração própria.

As críticas à judicialização da saúde são muitas. Dentre elas, identificamos: i) a interferência negativa no planejamento, na igualdade e na universalidade do SUS; ii) as falhas estruturais do Judiciário, como a ineficiência, a morosidade e os erros, impedem esse Poder de conceder um adequado acesso à saúde; iii) não é função do Judiciário criar políticas públicas; iv) a judicialização da saúde, ao estabelecer a responsabilidade solidária dos entes da federação nas ações de saúde, desorganiza o SUS; v) a judicialização desconsidera os limites econômicos, ferindo o princípio da reserva do possível; e vi) o Judiciário pode ser usado para atender aos interesses de mercado e não às necessidades sociais (59). 
Em relação à última crítica apontada, sabe-se que o campo jurídico pode ser uma via importante descoberta pelas indústrias para que os profissionais de saúde atuem em seu favor, sob argumentos tais como a defesa do direito universal à saúde e aos novos medicamentos e procedimentos médicos. As novas tecnologias em saúde, em muitos casos, são consumidas pela pressão do direito constitucional e do apelo emocional ao Sistema Judiciário (60).

O que se observa atualmente, no campo da saúde, é que os mais variados atores, entre eles associações de pacientes, advogados da indústria e médicos do SUS e particulares, expressam um claro interesse em permitir a todos o acesso a tecnologias de eficácia por vezes controversa (61). Para Campos et al. (62), a associação entre médicos e escritórios de advocacia nas solicitações dos medicamentos pode ser um indício de que a justiça e a medicina têm sido utilizadas para atender aos interesses da indústria farmacêutica. Chieffi e Barata (63) encontraram que, na cidade de São Paulo, mais de 70\% das ações movidas para certos medicamentos são de responsabilidade de um único advogado. Isso pode sugerir uma relação estreita entre o advogado e o fabricante do medicamento.

Alguns estudos, a partir da observação da existência de relação entre o aumento do número de ações judiciais que requisitam medicamentos e a incorporação destes ao SUS, apontam que a judicialização da saúde, por interferir demasiadamente nas políticas de saúde, transformou-se em pressão para incorporação de fármacos pelo setor público (64) (65) (54). Contrapondo-se a essa teoria, Souza et al. (66) afirmam que, apesar de as ações judiciais relativas à incorporação de tecnologias terem feito parte das discussões do plenário da CONITEC entre os anos de 2010 e 2015, esse não foi um fator decisivo para a tomada de decisão da Comissão. Ao contrário, esse estudo indicou que os membros da CONITEC seguiram o fluxo de incorporação de tecnologias regulamentado pela Lei $n^{\circ} 12.401 / 2011$, pelo Decreto $n^{\circ} 7.646 / 2011$ e pelo regimento interno da Comissão.

Como um dos principais impactos da judicialização da saúde, têm-se que o Judiciário se constitui como uma via de acesso à saúde que impacta no orçamento. Isso fica ainda mais crítico quando o ente federativo do qual se exige o cumprimento da decisão judicial é o município (67). O impacto orçamentário pode ser de tal ordem de grandeza que o sistema de saúde poderá não ter condições de sustentar-se por muito tempo (68).

Porém, é necessário compreender as consequências da atuação do Judiciário além dessas perspectivas. Ao identificarem que os medicamentos solicitados por meio da 
judicialização já estavam em formulários governamentais, Pepe et al. (31) e Biehl et al. (61) evidenciam possível desconhecimento ou dificuldade de acesso às vias institucionais do sistema público de saúde. É possível observar que existem vazios assistenciais e fragilidades no acesso às políticas públicas de saúde que ganham maior visibilidade com as ações judiciais, que por sua vez geram o debate necessário e conduzem ao alcance de soluções (69). Além disso, há a hipótese de que a judicialização possa contribuir para a universalidade e isonomia do SUS, uma vez que não privilegia apenas os demandantes, pois a ingerência judicial impulsiona a criação de políticas públicas que beneficiam a todos. Um forte exemplo foram as políticas de combate à AIDS (70).

\section{Considerações finais}

A judicialização da saúde refere-se a um fenômeno complexo, que tem servido a diferentes propósitos e realidades, fazendo com que o setor saúde viva um dilema em que a definição da judicialização enquanto solução ou problema não é tarefa simples. Essa polarização evidencia uma disputa sobre o conceito de valor da saúde, em que a compreensão da saúde enquanto mercadoria e oportunidade de fazer negócios se contrapõe à representação da saúde enquanto direito universal, um valor fundamental da sociedade, que não deve ser ofertado simplesmente segundo as regras de mercado.

A complexidade do fenômeno culmina na diversidade de intervenções nos diferentes países, em que o aumento impressionante de ações judiciais no campo da saúde gera conflitos entre garantir o direito à saúde e limitações em termos de competências constitucional e institucional.

Apesar dos reflexos negativos da judicialização da saúde, uma vez que a judicialização desconsidera os limites econômicos, ferindo o princípio da reserva do possível e promovendo desorganização e dificuldades no planejamento dos serviços de saúde públicos e privados, o fenômeno também apresenta pontos positivos. Notam-se seus reflexos positivos quando há a viabilização de alternativas terapêuticas benéficas que não estavam disponíveis no SUS; ou quando as ações judiciais influenciam a Administração Pública a incorporar novas tecnologias nos protocolos e diretrizes terapêuticas para aumentar o leque das opções terapêuticas; ou para fazer o gestor cumprir o que já está incorporado e já faz parte das listas de ofertas do SUS.

Diante do exposto, a encruzilhada da judicialização no Brasil demonstra um dilema entre vários caminhos a seguir, não havendo a possibilidade de escolha de apenas uma via 
9. Schulze CJ. Judicialização da saúde em números. Blog Abrange. 2020. [citado em 10 dez. 2020]. Disponível em: https://blog.abramge.com.br/saude-suplementar/judicializacaoda-saude-em-numeros/

10. Leitão LCA, et al. Judicialização da saúde na garantia do acesso ao medicamento. Revista de Salud Publica. 2014; 16(3): 360-370.

11. Ribeiro KD, Vidal JP. Uma análise da produção acadêmica sobre a evolução do fenômeno da judicialização da saúde no Brasil. Cadernos ibero-americanos de direito sanitário. 29 junho 2018; 7(2): 239-261.

12. Rother ET. Revisão Sistemática x Revisão Narrativa. Acta Paul Enferm. São Paulo, 2007; 20(2) [citado em 10 dez 2020]. Disponível em:

https://www.scielo.br/j/ape/a/z7zZ4Z4GwYV6FR7S9FHTByr/?lang=pt

13. Fachin O. Fundamentos de metodologia. 5 ed (rev). São Paulo: Saraiva; 2006. p. 1-9.

14. Duarte RP. Uma introdução ao Direito Comparado. 4 ed. Editora Almeidinha SA; 2016. p. $769-792$

15. Cardoso GV. O direito comparado na jurisdição constitucional. São Paulo. Revista Direito GV, Dezembro 2010; 6(2):469-492.

16. Tavares ALL. Contribuição do direito comparado às fontes do direito brasileiro. São Paulo: Prisma Jurídico. 2006; 5:59-77.

17. Filpo KPL. Conflitos Escolares, Espiral do Conflito e (por que não?) a mediação. Revista de Formas Consensuais de Solução de Conflitos. 2015; 1(1):96-113.

18. Sarlet IW, Timm LB (orgs.). Direitos fundamentais: orçamento e reserva do possível. Porto Alegre: Livraria do Advogado, 2008: 11-53 p.

19. Barcellos AP. A eficácia jurídica dos princípios constitucionais: o princípio da dignidade da pessoa humana. $3^{\mathrm{a}}$ ed. Rio de Janeiro: Renovar; 2011. 276 p.

20. Araújo EC, Araújo IB, Mendes GAM, Santos KV. A materialização do direito social à saúde pela via judicial e o confronto entre as teorias da reserva do possível e do mínimo existencial. In: Filpo K, Miranda MG, Silva RB, Pereira TR. Direitos humanos e fundamentais em perspectiva. Rio de Janeiro: Ágora21; 2019. 802p.

21. Brinks DM, Gauri V. The law's majestic equality? The distributive impact of judicializing social and economic rights. Perspect. Politics. 2014; 12:375-93.

22. Gloppen S. Litigation as a strategy to hold governments accountable for implementing the right to health. Health Hum. Rights. Janeiro 2008; 10:21-36

23. Lamprea E. The Judicialization of Health Care: A Global South Perspective. Annu. Rev. Law. Soc. Sci. 2017; 13:431-449. 
24. Horgerzeil H, Samson M, Vidal J, Rahmani-Ocora L. Is access to essential medicines as part of the fulfillment of the right to health enforceable through the courts? Lancet. 2006; 368:305-11.

25. Ngwena R. Escopo e limite da judicialização do direito constitucional à saúde na África do Sul: avaliação de casos com referência específica à justiciabilidade da saúde. São Paulo: Revista de Direito Sanitário. Julho/outubro 2013; 14(2): 43-87.

26. Vidal J, Di Fabio JL. Judicialización y acceso a tecnologías sanitarias: oportunidades y riesgos. Rev Panam Salud Publica. 2017; 41-137p.

27. Reveiz L, Chapman E, Torres R, Fitzgerald J, Mendoza ABM et al. Litigios por derecho a la salud en tres países de América Latina: revisión sistemática de la literatura. Revista Panamericana de Salud Pública. 2013; 33(3):213-222.

28. Nieto $\mathrm{E}$, Arango A. Costos de los servicios de salud tutelados y del proceso legal de las tutelas en Medellín, 2009. Rev Fac Nac Salud Publica. 2011; 29(3):223-31.

29. Machado MA, Acurcio F de A, Brandão CM, Faleiros DR, Guerra AA, Cherchiglia ML et al. Judicialization of access to medicines in Minas Gerais state, Southeastern Brazil. Rev Saude Publica. 2011; 45(3):590-8. 32.

30. Marques SB, Dallari SG. Garantia do direito social à assistência farmacêutica no Estado de São Paulo. Rev Saude Publica. 2007; 41(1): 101-7

31. Pepe VL, Ventura M, Sant'ana JM, Figueiredo TA, Souza VR, Simas L, Osorio-deCastro CG. Caracterização de demandas judiciais de fornecimento de medicamentos "essenciais" no Estado do Rio de Janeiro, Brasil. Cad Saude Publica. 2010; 26(3):461-71.

32. Loaiza OR, Morales M, Norheim OF, Wilson BM. Revisiting Health Rights Litigation and Access to Medications in Costa Rica: Preliminary Evidence from the Cochrane Collaboration Reform. Judicial enforcement of health rights: focus on Latin America. 2018; 20(1):79-91.

33. Lamprea E. Structural reform litigation, regulation and the right to health in Colombia. In F Bignami, D Zaring (ed). Comparative Law and Regulation: Understanding the Global Regulatory Process. Cheltenham, UK: Edward Elgar; 2016. 335-52p.

34. Chapman AR, Forman L, Lamprea E. Evaluating essential health packages from a human rights perspective. J. Hum. Rights. 2015; 16:142-59.

35. Nakamura FC, Caobianco NM. A judicialização do direito à saúde em uma perspectiva comparada: Brasil e Colômbia. Revista de Direito Sanitário. 2019; 20(1):63-85.

36. Zaring D. National rulemaking through trial courts: the big case and institutional reform. UCLA Law Rev. 2004; 51:1015-78

37.Gargarella R. 2011. Dialogic justice in the enforcement of social rights: some initial arguments. Yamin \& Gloppen. 2011; 232-45p. 
38.Defago MAP; Faúndes JMM. Conservative litigation against sexual and reproductive reproductive health policies in Argentina. Reproductive Health Matters 2014; 22(44):82-90.

39. Oliveira MRM, Delduque MC, Sousa MF, Mendonça AVM. Mediation: a way to disjudialize health. Temp Act Saúde Col [Internet]. 2016 [citado em 20 dez 2020]. Disponível em: https://www.arca.fiocruz.br/handle/icict/41901

40. Brasil. Constituição. Constituição da República Federativa do Brasil. 1988. [citado em: 11 dez. 2019]. Disponível em:

http://www.planalto.gov.br/ccivil_03/constituicao/constituicaocompilado.htm

41. Machado FRS, Dain S. Direito e saúde: contribuições para o estudo da judiciaização In: Asensi FD, Pinheiro R (org.). Direito Sanitário. Rio de Janeiro: Elsevier; 2012. 614p.

42. Oliveira VE. Judicialização de Políticas Públicas no Brasil. Rio de Janeiro: Editora Fiocruz; 2019. 332p.

43. Brasil. Decreto $n^{\circ} 7.646$, de 21 de dezembro de 2011. Dispõe sobre a Comissão Nacional de Incorporação de Tecnologias no Sistema Único de Saúde e sobre o processo administrativo para incorporação, exclusão e alteração de tecnologias em saúde pelo Sistema Único de Saúde - SUS, e dá outras providências. Brasília. 2011.

44. Bucci MPD. Contribuição para a redução da Judicialização da Saúde. Uma estratégia jurídico-institucional baseada na abordagem de direito e políticas públicas. Apud Bucci MPD, Duarte CS. Judicialização da saúde: a visão do poder executivo. Ed. Saraiva, São Paulo; 2017. 243p.

45. Pinheiro MC. Núcleos de Assessoramento Técnico: estratégia à judicialização da saúde? [Monografia]. Especialização em Gestão Pública. Escola Nacional de Administração Pública, Brasília. 2016. 48p.

46. Schulze CJ. A judicialização da saúde e o Conselho Nacional de Justiça. Revista de Doutrina da $4^{a}$ Região. Feveireiro 2014 [citado em 27 jan. 2019]; 58:12. Disponível em: http://www.revistadoutrina.trf4.jus.br/artigos/edicao058/Clenio_Schulze.html

47.TRF2. Judicialização da saúde no STF. Comitê de saúde CNJ-RJ. 2020 [citado em 16 dez 2020]. Disponível em: https://www10.trf2.jus.br/comite-estadual-de-sauderj/judicializacao/stf/

48. STF. Teses de Repercussão geral. 2020 [citado em 10 dez 2020]. Disponível em: http://www.stf.jus.br/portal/jurisprudenciaRepercussao/abrirTemasComRG.asp

49. Chieffi AL, Barata RB. Judicialização da política pública de assistência farmacêutica e eqüidade. Cad Saúde Pública. Agosto de 2009; 25(8):39-49.

50. Biehl J, Socal MP.; Amon J.J. The judicialization of health and the quest for state accountability: Evidence from 1,262 lawsuits for access to medicines in Southern Brazil Health and human rights.2016; 18(1): 209p. 
51. Borges DCL, Ugá MAD. Conflitos e impasses da judicialização na obtenção de medicamentos: as decisões de $1^{a}$ instância nas ações individuais contra o Estado do Rio de Janeiro em 2005. Caderno Saúde Pública. 2010 [citado em 10 dez 2020]. Disponível em: https://www.scielo.br/j/csp/a/Zgc6jhqCKFgBnKZ4jFcyg7F/abstract/?lang=pt

52. Ventura M, Simas L, Pepe VLE, Schramm FR. Judicialização da saúde, acesso à justiça e a efetividade do direito à saúde. Physis: Revista de Saúde Coletiva. 2010 [citado em 11 dez 2020]; 20(1). Disponível em:

https://www.scielo.br/j/physis/a/35xXdQXR9JrdvpPmtkktL9F/?lang=pt

53. Wang DWL, Vasconcelos NP, Oliveira VE, Terrazas FV. Os impactos da judicialização da saúde no município de São Paulo: gasto público e organização federativa. Rev Adm Publ. 2014; 48(5):1191-1206.

54. Guimarães R. Incorporação tecnológica no SUS: o problema e seus desafios. Ciência e Saúde Coletiva. 2014; 19(12):4899-4908.

55. Bittencourt GBO. "Estado da Arte" da produção acadêmica sobre o fenômeno da judicialização da saúde no Brasil. Cad. Ibero-Amer. Dir. Sanit. Brasília, 2016; 5(1):102-121.

56. Barcelos PC. Perfil de demandas judiciais de medicamentos da Secretaria de Estado da saúde do Espírito Santo: um estudo exploratório. Caderno Saúde Pública. 2010; 26(1):59- 69 .

57. Machado TRC. Judicialização da saúde: analisando a audiência pública no Supremo Tribunal Federal. Rev. bioética. 2014; 22(3):561-568.

58. Aith FMA, Bujdoso Y, Nascimento PR, Dallari SG. Os princípios da universalidade e integralidade do SUS sob a perspectiva da política de doenças raras e da incorporação tecnológica. Revista de Direito Sanitário. 2014 [citado em 11 dez 2020]; 15(1). Disponível em: https://www.revistas.usp.br/rdisan/article/view/82804

59. Paula CEA, Bittar CML. Judicialização da saúde e seus reflexos na gestão do sistema único de saúde (SUS). Rev Dir Hum Efet (Brasília) [Internet]. 2017; 3(1):19-41. Disponível em: https://indexlaw.org/index.php/revistadhe/article/view/1866

60. Carvalho G. Saúde: o tudo para todos que sonhamos e o tudo que nos impingem os que lucram com ela. Saúde em Debate. 2005; 29(69):99-104.

61. Biehl J. Petryna A. Tratamentos jurídicos: os mercados terapêuticos e a judicialização do direito à saúde. História, Ciências, Saúde - Manguinhos. Janeiro-março. 2016; 23(1):173-192

62. Campos Neto OH, Acurcio FA, Machado MAA, Ferré F, Barbosa FLV, Cherchiglia ML et al. Médicos, advogados e indústria farmacêutica na judicialização da saúde em Minas Gerais, Brasil. Rev Saúde Pública. 2012; 46(5):784-90. 


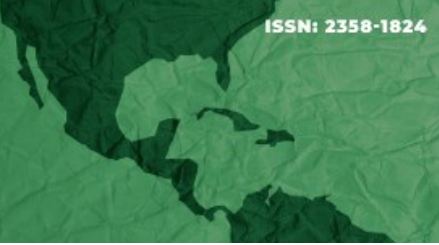

63. Chieffi, AL, Barata RCB. Ações judiciais: estratégia da indústria farmacêutica para introdução de novos medicamentos Rev de Saúde Pública. 2010; 44(3):421-429.

64. Diniz D, Medeiros M, Schwartz IDD. Consequências da judicialização das políticas de saúde: custos de medicamentos para as mucopolissacaridoses. Cad. Saúde Pública. 2012; 28(3):479-489.

65.Torres IDC. Judicialização do acesso a medicamentos no Brasil: uma revisão sistemática [dissertação]. Salvador: Universidade Federal da Bahia, Instituto de Saúde Coletiva; 2013. $86 \mathrm{p}$

66. Souza KAO, Souza LEPF, Lisboa ES. Ações judiciais e incorporação de medicamentos ao SUS: a atuação da Conitec. Saúde debate. 2018; 42(119):837-848.

67. Massau GP. O impacto da judicialização da saúde na comarca de Pelotas. [citado em 5 maio 2018]. Disponível em: http://www.revistas.usp.br/rdisan/article/view/88357/91233

68. Chaves O, Zerbini T. Judicialização da medicina e o impacto orçamentário na administração pública. Saúde, Ética \& Justiça. 2017; 22(2):58-65.

69. Neto et al. Médicos, advogados e indústria farmacêutica na judicialização da saúde em Minas Gerais, Brasil. Rev de Saúde Pública. 2012; 46:784-790.

70. Oliveira VE, Noronha LNT. Judiciary-Executive relations in policy making: the case of drug distribution in the State of São Paulo. BPSR, 2011; 5(2):10-38.

\section{Colaboradores}

Todos os autores contribuíram com a concepção, elaboração, redação, revisão e aprovação do artigo. 